\title{
Formação de professores em educação especial no "Plano Nacional de Educação Proposta da Sociedade Brasileira" de 1997
}

\author{
Mariana Luzia Corrêa Thesing \\ Ana Paula dos Santos Ferraz \\ Bruna de Assunção Medeiros \\ Fabiane Adela Tonetto Costas
}

\section{Resumo}

A formação de professores está relacionada às escolhas político-pedagógicas diante de determinadas concepções de sociedade, de homem e de educação. Ante essa premissa, são analisadas as políticas públicas referentes à formação de professores, especialmente os de educação especial, e suas relações com o "Plano Nacional de Educação Proposta da Sociedade Brasileira" (PNE-Coned), elaborado pela comissão organizadora do II Congresso Nacional de Educação (Coned), em 1997. A metodologia adotada foi a análise documental. Conclui-se que as políticas públicas referentes à formação de professores em vigor no Brasil parecem não contribuir efetivamente com esses processos em um viés emancipatório. Os resultados também apontam que o PNE-Coned, elaborado coletivamente por associações e entidades da sociedade civil, apresenta metas e diretrizes ainda contemporâneas para os processos de formação de professores.

Palavras-chave: educação especial; formação de professores; plano nacional de educação; Congresso Nacional de Educação; Fórum Nacional em Defesa da Escola Pública. 


\section{Abstract \\ Teacher training in special education in the "Plano Nacional de Educação Proposta da Sociedade Brasileira" from 1997}

Teacher training is related to political-pedagogical choices before certain conceptions of society, mankind and education. Considering this premise, the article analyses public policies on teacher training, mainly the ones for special education teachers, and their relationship with the "Plano Nacional de Educação Proposta da Sociedade Brasileira", which was formulated by the organizing committee of the II Congresso Nacional de Educação (Coned - National Congress of Education), in 1997. The methodology employed was the documental analysis. The conclusion is that the current public policies regarding teacher training in Brazil do not seem to contribute effectively to these processes in an emancipatory bias. The results also indicate that the PNE-Coned, prepared collectively by associations and civil society entities, presents goals and guidelines that are still contemporary for teacher training processes.

Keywords: special education; teacher training; national education plan; National Congress of Education; National Forum in Defense of Public School.

\section{Introdução}

A política educacional brasileira passou por grandes transformações, principalmente no decorrer da última década, em um período de mudanças conceituais que influenciaram os processos educacionais nos espaços escolares. Grande parte dessas mudanças advém do movimento Educação para Todos, que emergiu na década de 1990 e ganhou força nos últimos anos com a proposição da educação inclusiva, preconizada por organismos internacionais. Esse movimento, decorrente da Declaração Mundial sobre Educação para Todos, aprovada na Conferência de Jomtien em 1990, e de suas repercussões em prol da garantia da educação como um direito subjetivo e constitucional, teve como objetivo central a redução da pobreza e das desigualdades sociais. Com esse propósito, ao aliar a pobreza e as desigualdades sociais às diferentes formas de exclusão, dentre elas a educacional, a inclusão passou a ser compreendida como a solução para superar tais problemas sociais. Nesse contexto, em que a inclusão passa a ser entendida como a resposta necessária a questões sociais e econômicas, "a educação inclusiva" ganha força como estratégia e slogan da "educação para todos" na política educacional (Garcia, 2014, p. 123) e pressupõe novos saberes e fazeres dos professores para atuação nesse "novo rumo" da educação.

Contudo, entende-se que os professores precisam compreender com criticidade o processo educacional para "dar conta" das exigências do seu local de trabalho e para ensinar "tudo a todos". Diante disso, este texto tem o objetivo 
de problematizar alguns elementos das políticas públicas ${ }^{1}$ referentes à formação de professores da educação especial.

Para essa discussão, a partir de uma pesquisa documental, resgatou-se o Plano Nacional de Educação: Proposta da Sociedade Brasileira (doravante PNEConed), de 1997, com a finalidade de desvelar as concepções, metas e diretrizes elaboradas coletivamente sobre o processo de formação de professores. A escolha desse documento para a escrita do presente texto justifica-se por sua importância para a história da educação brasileira, uma vez que foi elaborado de forma coletiva por diferentes associações e entidades, em defesa da escola pública e do direito subjetivo à educação. Desse modo, este artigo propõe um diálogo entre as diretrizes para a formação dos profissionais da educação previstas nesse plano e os encaminhamentos realizados com base em decretos, leis e resoluções mais recentes que tratam da formação de professores no Brasil, especificamente dos professores de educação especial. Consideramos necessária essa discussão, pois o modelo de formação de professores atualmente proposto parece estar vinculado a processos de formação aligeirada e/ou desintelectualizada.

\section{Algumas considerações sobre o PNE-Coned}

Trata-se de um documento elaborado em 1996 e 1997, de forma participativa, entre os amplos setores da educação, que propunha novas perspectivas para a educação no Brasil, distanciadas das propostas já desenvolvidas historicamente. O plano foi uma iniciativa do Fórum Nacional em Defesa da Escola Pública (FNDEP) - anteriormente denominado Fórum Nacional da Constituinte (criado em 1986) -, formado por mais de 30 entidades sindicais e estudantis, associações acadêmicas e científicas, e atuante em diferentes momentos da história brasileira.

Antes da elaboração desse plano, o FNDEP já estava envolvido em várias frentes de luta pela educação pública, mobilizando diversas ações voltadas para a defesa da escola pública e de qualidade. O FNDEP mobilizou ações para a aprovação na Constituição Federativa do Brasil, em 1988, do Capítulo III, Seção I, intitulada Da Educação (arts. 205 a 214), apesar da não aprovação de todas as propostas.

Entre os anos de 1988 e 1996, o FNDEP, a partir da discussão com educadores brasileiros, construiu um documento como proposta de lei de diretrizes e bases. Nele defendia um renovado conjunto de leis para a educação nacional, que deveria ser orientada por princípios pautados pela concepção de educação pública, laica, gratuita, democrática e de qualidade social, como direito de todos e dever do Estado. Então, apresentou o Projeto de Lei n 1.258/1988 ao Congresso Nacional e, apesar de se tratar de um documento elaborado por diversos educadores brasileiros com base em intensas discussões, foi derrotado pela aprovação do Projeto de Lei n 73 , de fevereiro de 1995, que resultou, em 1996, na Lei $n^{\circ} 9.394$ - a atual Lei de Diretrizes e Bases da Educação Nacional (LDB).

${ }^{1}$ A legislação base encontra-se na Lei de Diretrizes e Bases da Educação Nacional (LDB), de 1996, e as alterações de 2001, 2006, 2008, 2009 
Diante de um cenário de globalização neoliberal e de processos de privatização do ensino, especialmente no ensino superior, o FNDEP decidiu dar prosseguimento às discussões sobre a educação pública, elaborando um plano nacional de educação, previsto na Constituição Federal de 1988 (art. 214), defendido na LDB recémaprovada, mas que ainda não tinha sido elaborado pelos governos que estavam no poder. Desse modo, por meio do método participativo-democrático em diversos eventos no Brasil, o documento foi elaborado entre 1996 e 1997 e sistematizado pela comissão organizadora do II Congresso Nacional de Educação (Coned). No ano de 1997, foi apresentado com o título Plano Nacional de Educação Proposta da Sociedade Brasileira, tendo sido elaborado com a participação de vários educadores brasileiros e entidades sociais.

Contudo, assim como o que ocorreu com a proposta da LDB elaborada de forma participativa pela sociedade brasileira, esse plano foi substituído por outro, organizado às pressas e aprovado pelo governo de Fernando Henrique Cardoso (em 1998). Sobre esse processo, Bollmann (2010, p. 673) afirma que,

\begin{abstract}
pela primeira vez na história da educação brasileira, um projeto educacional do porte de um plano nacional é elaborado pelo conjunto da sociedade civil organizada em um fórum nacional, após ter passado por amplo, público e democrático processo de discussão entre os anos de 1996 e 1997, que culminou com a aprovação por mais de 5 mil pessoas presentes no II Coned, em novembro de 1997, em Belo Horizonte, MG.
\end{abstract}

O documento, a partir da apresentação do diagnóstico da educação nacional, faz considerações sobre a "organização da educação nacional", sobre os "níveis e modalidades de educação" e sobre a "formação de profissionais da educação". Apresenta em seu texto, com caráter crítico e contributivo, um projeto de educação comprometido com ideais democráticos, defendendo os princípios de uma educação laica, gratuita e de qualidade para todos, considerada dívida histórica da nação para com o seu povo, que sofreu com uma história educacional marcada por exclusões e retrocessos. De acordo com o plano, a sua elaboração estava fundamentada pelas aspirações das diversas entidades, que representavam a sociedade brasileira e estavam voltadas à defesa de condições mais igualitárias e mais justas para toda a população e ao direito a uma educação escolarizada de qualidade. Segundo o documento,

\footnotetext{
as visões que subjazem a este plano indicam seu referencial maior: mudar o modelo social vigente, transformar a sociedade, tornando-a de fato democrática. Tal transformação requer um projeto de desenvolvimento nacional que tenha como centro, em suas dimensões econômica, social, cultural e política, o aperfeiçoamento e a dignificação do homem, não do mercado. (Coned, 1997, p. 1).
}

Entre os temas que compõem o PNE-Coned, o que nos interessa neste texto é o tópico Formação dos Profissionais da Educação. Nele, são apresentadas as diretrizes e metas que se definem como ações necessárias para uma formação docente embasada em conhecimentos teórico-políticos, comprometida com uma escola que se quer democrática. Na leitura desse documento, identifica-se um conjunto de necessidades contemporâneas às nossas vivências, considerando 
as políticas de formação de professores de forma geral e, especificamente, dos professores da educação especial.

\section{PNE-Coned e as políticas públicas: a formação de professores}

Nesse plano, a educação é considerada um instrumento de emancipação humana e de transformação social. Defende-se que os processos educativos devem ser ofertados de forma mais abrangente e democrática, haja vista o texto da Constituição Federal de 1988. O PNE-Coned foi organizado com base na necessidade de defesa da escola pública, da educação de qualidade como um direito subjetivo de todos os cidadãos, com a oferta de infraestrutura adequada e formação de profissionais para atuarem nas escolas brasileiras. Trata-se de um documento que denuncia o descaso e a indiferença governamental que marcaram a história da educação nacional - cujos fatos revelam decisões descomprometidas em relação à educação das classes populares.

Com o propósito de denúncia, o documento arrola alguns indicadores da formação dos profissionais da educação, entre os quais: "esvaziamento dos cursos de formação básica, tratamento inadequado e insuficiente da formação continuada, condições inadequadas de trabalho, salários indignos, indefinição de carreira, entre outros" (PNE-Coned, 1997, p. 14). Considerando esse cenário, o plano aponta para uma formação desejável, que seria exigida em curto para médio prazo, para todos os níveis e modalidades, no âmbito da educação superior, em cursos de licenciatura plena.

Contudo, apesar da precariedade da formação de professores denunciada por esse documento em 1997 e mesmo com as alterações na Lei no 9.394/1996 realizadas pela Lei $n^{\circ}$ 12.796/2013, continua em vigor a exigência da habilitação em curso de nível médio, na modalidade normal, como formação mínima para a atuação no magistério. Além disso, apesar da utilização do termo "preferencialmente" quando referido o formato presencial dos cursos, admite-se a formação inicial de professores mediante educação a distância (EaD). Assim, consideramos necessário problematizar as modalidades de formação ainda aceitas pela LDB (Lei nº 9.394/1996 e suas alterações), porque compreendemos que um curso de curta duração, pela restrição de tempo, pode não contemplar uma formação inicial de professores embasada em conhecimentos teórico-políticos que fundamentem as práticas pedagógicas desses profissionais.

Entendemos que a formação docente, num viés emancipatório, deve assumir como intencionalidade a formação tanto para o "mundo do trabalho" quanto para o "mundo da vida". Esse tipo de formação deve ter como características essenciais um conjunto de conhecimentos didático-metodológicos que habilitam o professor para o "mundo do trabalho", e conhecimentos teórico-políticos, relacionados aos fundamentos da educação, que o capacitam, numa formação omnilateral, para o "mundo da vida". Nos currículos de formação dos professores, além dos conhecimentos instrumentais para o exercício da docência, que possibilitem 
os processos de ensinar e de aprender nos espaços escolares, também devem ser priorizados conhecimentos teórico-políticos voltados para formar professores que compreendam, a partir de diferentes concepções de homem, de educação e de sociedade, os processos educacionais em que estão inseridos.

Mais do que saber quais instrumentos metodológicos e recursos didáticos utilizar no processo de ensinar os estudantes, é preciso que os professores saibam quais as perspectivas epistemológicas que embasam os processos de ensinar e aprender na escola. Sem um conjunto de saberes teórico-políticos fundantes, corre-se o risco de termos propostas de formação de professores meramente instrumentais. Essa forma de compreender a formação do professor apenas pelo campo da prática, desvinculada do campo teórico, de acordo com Garcia (2013, p. 110-111), guarda como pressuposto que "os professores devem ser formados no próprio ambiente de trabalho, nas escolas, e que a base de sua formação é a própria prática docente, sendo dispensável uma formação universitária e o estudo das teorias pedagógicas, entre outros conhecimentos". Para a autora, esse modo de pensar a formação do professor serve como estratégia de desintelectualização, uma vez que prioriza a prática em detrimento da teoria, favorecendo a adaptação desse profissional às exigências impostas pelas políticas educacionais e não aos seus movimentos políticos.

Nessa perspectiva, de acordo com Shiroma e Santos (2014), reduzir a formação do professor à capacitação técnica, para o uso de estratégias pedagógicas, associa-se a uma formação tecnicista, desvinculada de conhecimentos teóricofundantes na formação dos professores.

Como alerta Gramsci (2011), a tentativa de reduzir as ações dos sujeitos à operacionalização de tarefas cotidianas faz parte da grande política de manutenção da hegemonia burguesa. Confinar a qualidade da educação ao que se pode mensurar nas avaliações é abstrair da educação a relevância social, é restringi-la a uma atividade técnica, obliterando sua dimensão política. (Shiroma; Santos, 2014, p. 41).

Diante do exposto, o professor com uma formação voltada apenas para a prática, sem pretensão de questionar seu papel e atribuições em seu local de trabalho, torna-se um profissional técnico, gestor de recursos e processos pedagógicos, adaptável e reconvertido: um professor flexível e multifuncional modelo esse solicitado pelos discursos que embasam as políticas vigentes. A reconversão docente, segundo Evangelista e Triches (2012), configura-se como um processo de transformação do perfil docente, em que um modelo de professor considerado ultrapassado (tradicional, inflexível, autoritário) é substituído por um novo e necessário professor (aprendente, flexível, autoridade, reflexivo) para dar conta da proposição de um sistema educacional que se quer inclusivo. Nesse processo, surge a figura de um "superprofessor", com inúmeras qualidades, que é ao mesmo tempo objeto e instrumento da/para a reforma educacional proposta. De acordo com as autoras, há um real alargamento da formação e do campo de atuação profissional dos professores, somado a uma possível restrição de fundamentação teórica nos processos formativos desses profissionais. Esse mecanismo é caracterizado por Garcia (2013, p. 112) como um processo no qual "[...] reconverter os professores 
passa a ser uma estratégia política fundamental para produzir alterações na mentalidade da população, de modo continuado, ao longo da vida, e na direção necessária aos interesses do projeto societário hegemônico".

Assim, os professores reconvertidos são aqueles que, mesmo aparentemente, se submetem a abandonar seu modo tradicional para ser um "novo" professor, um professor multifuncional, polivalente, aprendendo ao longo da vida para dar conta das demandas a ele atribuídas pelo "novo" perfil do professor de Educação Especial. ${ }^{2} \mathrm{E}$, muitas vezes, atribuindo a si mesmo os fracassos produzidos na escola.

Além dos documentos já citados, a restrição da formação com pressupostos teóricos, aliada a um possível alargamento da função docente, também pode ser evidenciada na Resolução CNE/CP n $n^{\circ}$ 1/2006, que institui as diretrizes curriculares nacionais para o curso de pedagogia. Nessa resolução, extinguem-se as habilitações específicas desse curso e propõe-se uma nova concepção para a formação de professores - capazes de atuar em diferentes instâncias e com grupos diferenciados. Amplia-se o campo de atuação para esse profissional, que deve ser habilitado para o trabalho com diferentes níveis de ensino (educação infantil, ensino fundamental, ensino médio, educação profissional) e possuir vivências formativas para encarar diferenciadas realidades: "a educação de pessoas com necessidades especiais, a educação do campo, a educação indígena, a educação em remanescentes de quilombos, em organizações não governamentais, escolares e não escolares, públicas e privadas" (Brasil. CNE, 2006, p. 5). No caso dos professores de educação especial, segundo Michels (2011, p. 82),

[...] a formação docente proposta pelas atuais diretrizes para os cursos de Pedagogia trata da educação dos deficientes de maneira generalizada. Não há uma preocupação expressa relativa à educação desses alunos. Ao mesmo tempo, há uma pulverização de sujeitos, os quais essa formação docente deve ter como alvo (índios, remanescentes de quilombolas, negros, deficientes), e uma diversificação de espaços onde poderá atuar o profissional.

No PNE-Coned, entre outras considerações, está expressa a necessidade de que a formação de professores deve ser "responsabilidade sobretudo das universidades, para que ocorra em patamar de qualidade social, política e pedagógica garantido pela indissociabilidade das funções de pesquisa, ensino e extensão e das relações entre teoria e prática" (Coned, 1997, p. 68). Além disso, indica-se a atividade de pesquisa como princípio formativo fundante, tendo em vista a "sólida formação teórica em todas as atividades curriculares, nos conteúdos específicos a serem ensinados na educação básica, em todos os seus níveis e modalidades, e nos conteúdos especificamente pedagógicos" (p. 68).

A EaD também é apontada no documento como um processo formativo que deve ser suplementar aos processos de formação docente e vinculado às universidades. Isso porque, de acordo com o texto, a educação presencial deve ser predominante a fim de "proporcionar formação cultural mais ampla, que abra novos horizontes na atuação profissional" (Coned, 1997, p. 68). A EaD é considerada meio suplementar

\footnotetext{
${ }^{2}$ Leia-se Resolução CNE/CEB no 4/2009 (Brasil. CNE, 2009).
} 
à formação dos profissionais da educação, pois esses deveriam vivenciar processos de formação de forma coletiva, em seus espaços de trabalho, que tivessem como "objetivo e finalidade a reflexão sobre a prática educativa e a busca de mecanismos necessários e adequados ao seu aperfeiçoamento técnico, ético e político" (p. 69). Contudo, o que se vê em nossos dias é uma oferta avassaladora de cursos de formação de professores, inicial e continuada, para a qualificação dos profissionais na modalidade a distância. Sobre os processos de EaD para a formação de professores, Pertile (2014, p. 84) afirma que,

embora os cursos na modalidade a distância, online, abarquem a formação de grande quantidade de profissionais e pareçam uma estratégia convidativa e confortável, escondem uma formação docente limitada e aligeirada que, supostamente, é justificada pela urgência de formar o profissional para uma tarefa imediata. Dessa forma, o professor enfrenta o dilema de conduzir o processo de ensino/aprendizagem rumo à humanização dos alunos, quando sua própria formação é comprometida [...].

Nesse sentido, considera-se que esse tipo de formação pode estar atrelado a uma formação em grande escala, nem sempre embasada por concepções que primam pela formação de novos professores com fundamentação teórico-política. A EaD realizada nesses moldes, aliada à formação em serviço dos educadores, estaria comprometida com processos formativos que levam à desintelectualização dos professores. Esses cursos, com rasteira formação teórica, centrada em ensinar técnicas e recursos para "o fazer", inviabilizariam a reflexão teórico-política desses profissionais acerca de seus objetos de trabalho. Nessa perspectiva, segundo Garcia (2013, p. 115), "há uma preocupação em formar/certificar na modalidade a distância um grande número de professores, muitos dos quais não têm formação inicial para atuar na educação especial, mas que são reconvertidos, no sentido de mudança do campo de atuação mediante tais cursos".

Entende-se que as políticas públicas vigentes sobre formação de professores estão centradas em uma lógica economicista, em que a formação generalista, a distância e esvaziada de fundamentação teórica não contribui para a educação pública de qualidade vislumbrada no texto do PNE-Coned. As consequências para a educação brasileira pautada pelas atuais políticas públicas podem ser desastrosas, principalmente aquelas voltadas para o público da educação especial, se não repensarmos o processo de formação de professores, pois, de acordo com Garcia (2013, p. 117),

ao contrário do que os discursos inclusivos têm contribuído para disseminar, não percebemos nesse modelo educacional elementos que permitam vislumbrar uma ruptura com a reprodução do modelo de sociedade. Nessa direção, afirmamos a funcionalidade de tais políticas e suas trágicas consequências para a educação básica e seus professores.

Diante dessa formação polivalente de um professor multifuncional, capacitado para o trabalho com diferentes grupos, questiona-se a qualidade dos processos formativos nesses moldes, já que o tempo de formação desses profissionais destinado ao aprofundamento em estudos teóricos pode se restringir diante de tantas demandas a serem assumidas em seus campos de atuação. 


\section{Educação especial e formação de professores: algumas considerações}

A educação especial é entendida como uma modalidade de ensino na educação regular, que deve ser desenvolvida preferencialmente na rede pública de ensino, a partir da premissa de que o ensino gratuito é direito de todos e dever do Estado. De acordo com o documento em análise, deverão ser garantidas todas as condições para a sua real efetivação, tendo como prioridades:

[...] a garantia de vagas no ensino regular para a diversidade de graus e tipos de deficiência;

a elaboração de projetos pedagógicos que se orientem pela política de inclusão e pelo compromisso com a educação escolar desses alunos;

a alocação, nos sistemas locais de ensino, dos necessários recursos pedagógicos especiais para apoio aos programas educativos e ações destinadas à capacitação de recursos humanos para atender as demandas desses alunos. (Coned, 1997, p. 44).

O tema da educação especial na perspectiva da educação inclusiva ganhou relevante espaço no cenário educacional a partir dos anos 2000. Daí em diante, são deixados de lado os discursos da perspectiva integradora (defendida nos anos 1990) para entrar em cena a proposta inclusiva. Tendo em vista essa nova forma de compreender a educação especial e suas relações com a escolaridade regular, outras formas de pensar embasaram as políticas públicas que regem a formação de professores e a caracterização dos espaços escolares inclusivos. Segundo Garcia (2014, p. 125), "ao ser apropriado pelas discussões no campo das políticas, o termo inclusão, nas suas diferentes dimensões (social, educacional, escolar, digital), aparece acompanhado de uma aura de 'inovação' e 'revolução', até mesmo como 'paradigma social'"

Nesse contexto, a Resolução CNE n⿳0 2/2001, que institui as diretrizes nacionais para a educação especial na educação básica, apresenta, além de considerações sobre a educação especial na escola regular, a necessidade da formação de professores capacitados e especializados que devem atuar, segundo o documento, de forma articulada no ensino regular:

Art. $18[\ldots]$

§1 ${ }^{\circ}$ São considerados professores capacitados para atuar em classes comuns com alunos que apresentam necessidades educacionais especiais aqueles que comprovem que, em sua formação, de nível médio ou superior, foram incluídos conteúdos sobre educação especial adequados ao desenvolvimento de competências e valores para:

I - perceber as necessidades educacionais especiais dos alunos e valorizar a educação inclusiva;

II - flexibilizar a ação pedagógica nas diferentes áreas de conhecimento de modo adequado às necessidades especiais de aprendizagem;

III - valiar continuamente a eficácia do processo educativo para o atendimento de necessidades educacionais especiais;

IV - atuar em equipe, inclusive com professores especializados em educação especial. 
$\S 2^{\circ}$ São considerados professores especializados em educação especial aqueles que desenvolveram competências para identificar as necessidades educacionais especiais para definir, implementar, liderar e apoiar a implementação de estratégias de flexibilização, adaptação curricular, procedimentos didáticos pedagógicos e práticas alternativas, adequados ao atendimentos das mesmas, bem como trabalhar em equipe, assistindo o professor de classe comum nas práticas que são necessárias para promover a inclusão dos alunos com necessidades educacionais especiais.

$\S 3^{\circ}$ Os professores especializados em educação especial deverão comprovar:

I - formação em cursos de licenciatura em educação especial ou em uma de suas áreas, preferencialmente de modo concomitante e associado à licenciatura para educação infantil ou para os anos iniciais do ensino fundamental;

II - complementação de estudos ou pós-graduação em áreas específicas da educação especial, posterior à licenciatura nas diferentes áreas de conhecimento, para atuação nos anos finais do ensino fundamental e no ensino médio. (Brasil. CNE, 2001, p. 5).

Além disso, no $\S 4^{\circ}$ do art. 18, defende-se a formação continuada dos professores e afirma-se a responsabilidade das instâncias educacionais da União, dos estados e municípios em ofertá-la.

A Política Nacional de Educação Especial na Perspectiva da Educação Inclusiva, além de traçar diretrizes para o atendimento educacional especializado (AEE) dos estudantes com deficiências, define que a formação do profissional para atuar na educação especial deve ter

[...] como base da sua formação, inicial e continuada, conhecimentos gerais para o exercício da docência e conhecimentos específicos da área. Essa formação possibilita a sua atuação no atendimento educacional especializado, aprofunda o caráter interativo e interdisciplinar da atuação nas salas comuns do ensino regular, nas salas de recursos, nos centros de atendimento educacional especializado, nos núcleos de acessibilidade das instituições de educação superior, nas classes hospitalares e nos ambientes domiciliares, para a oferta dos serviços e recursos de educação especial. (Brasil. MEC, 2008).

Além desses conhecimentos, esse profissional precisa saber sobre a gestão do sistema educacional inclusivo para garantir a intersetorialidade das ações. Com isso, percebem-se as múltiplas atribuições do profissional da educação especial no âmbito da escola regular, ratificadas pela Resolução CNE n 4/2009, que institui diretrizes operacionais para o AEE na educação básica, modalidade educação especial, e define, em seu art. 12, que a formação para a atuação no AEE deve ser embasada pela formação inicial que habilite para o exercício da docência e pela formação específica para a educação especial, sem estabelecer em quais níveis essa formação específica deverá ser realizada. O documento também elenca as atribuições desse professor:

Art. 13. São atribuições do professor do atendimento educacional especializado:

I - identificar, elaborar, produzir e organizar serviços, recursos pedagógicos, de acessibilidade e estratégias considerando as necessidades específicas dos alunos público-alvo da educação especial;

II - elaborar e executar plano de atendimento educacional especializado, avaliando a funcionalidade e a aplicabilidade dos recursos pedagógicos e de acessibilidade; 
III - organizar o tipo e o número de atendimentos aos alunos na sala de recursos multifuncionais;

IV - acompanhar a funcionalidade e a aplicabilidade dos recursos pedagógicos e de acessibilidade na sala de aula comum do ensino regular, bem como em outros ambientes da escola;

V - estabelecer parcerias com as áreas intersetoriais na elaboração de estratégias e na disponibilização de recursos de acessibilidade;

VI - orientar professores e famílias sobre os recursos pedagógicos e de acessibilidade utilizados pelo aluno;

VII - ensinar e usar a tecnologia assistiva de forma a ampliar habilidades funcionais dos alunos, promovendo autonomia e participação;

VIII - estabelecer articulação com os professores da sala de aula comum, visando à disponibilização dos serviços, dos recursos pedagógicos e de acessibilidade e das estratégias que promovem a participação dos alunos nas atividades escolares. (Brasil. CNE, 2009, p. 3).

Nessa perspectiva, esses documentos corroboram a multifuncionalidade do professor de educação especial, que deve ter suas funções voltadas para o atendimento do público-alvo dessa modalidade em sua diversidade, tornando-se um gestor de recursos pedagógicos e dos processos inclusivos na escola. Logo, ele se configura como um profissional multifuncional e generalista, formado para atuar em várias frentes nos processos inclusivos. É um profissional formado com uma base de conhecimentos instrumentais para o trabalho, numa perspectiva gerencialista em relação aos recursos disponíveis para os processos inclusivos nas instituições onde atua.

Nessa discussão, Michels (2011, p. 83), ao ter como foco a Política Nacional da Educação Especial na Perspectiva da Educação Inclusiva, promulgada em 2008, faz uma análise sobre a multifuncionalidade do trabalho do professor de educação especial e afirma que "[...] não encontramos, nesses documentos, uma preocupação explícita em relação ao papel do professor referente à lida com conhecimento. Esta parece ser uma função secundarizada, ou 'antiga', dentre as tarefas docentes", minimizando suas ações à gestão de recursos. E ainda afirma que,

[...] quando se priorizam o ensino de técnicas e métodos específicos para o trabalho com alunos com deficiência, estaríamos abrindo mão de uma formação teórica. Esse parece ser o encaminhamento dado, na atualidade, aos professores de maneira geral, não somente aos da educação especial. (Michels, 2011, p. 86).

Pertile (2014, p. 69) corrobora as ideias de Michels (2011) e ressalta que no AEE desenvolvido pelos professores de educação especial "há o afastamento dos propósitos pedagógicos [...] e a redução da atividade docente e, consequentemente, a redução das possibilidades de aprendizagem". Pertile (2014, p. 80, 81), ao discutir a ideia da multifuncionalidade dos professores de educação especial, afirma que a supressão do trabalho com os conteúdos escolares acarreta a "descaracterização da atividade do professor" e questiona a "viabilidade da execução de tarefas tão diversas por um mesmo profissional". 
Diante do movimento de formar os professores para atuação generalista, Garcia (2014) apresenta uma discussão acerca das políticas de formação de professores articulada ao campo da educação especial e, assim como Michels (2011), aponta a reconversão docente como um processo vinculado à estratégia de convencimento dos professores sobre sua responsabilidade pela resolução de problemas sociais mediante a inclusão na escola. Segundo essas autoras, a inclusão é veiculada como algo que pode mudar a sociedade, torná-la mais pacífica, comprometida com a equalização social. Os professores, nesse contexto, estariam envolvidos pelo discurso que os responsabiliza diante de possíveis fracassos na escola inclusiva (Garcia, 2014). Segundo a autora, nas políticas educacionais relacionadas aos processos de formação de professores há menos preocupação com a qualificação docente e maior ênfase nos instrumentos de controle e conformação dos professores.

\footnotetext{
Os discursos que sustentam as políticas de inclusão expõem uma "solução" ou "fórmula" para resolver os problemas sociais, econômicos, políticos e educacionais existentes nas sociedades contemporâneas. Para tanto, esteiam-se em uma trama de conceitos "politicamente corretos" na tentativa de construir uma linguagem de "mudança social" que motive os sujeitos sociais a aderir aos projetos divulgados. (Garcia, 2014, p. 132).
}

Nesse contexto, Pertile (2014), levando em consideração as Notas Técnicas no 9/2010 (Brasil. MEC, 2010a) e no 11/2010 (Brasil. MEC, 2010b), que apresentam as atribuições do professor de educação especial, chama a atenção para a responsabilização imputada a esse profissional e destaca que, entre essas atribuições, "é cooptado pelo discurso melodioso da educação inclusiva" e possui a "incumbência de, em nome da conscientização do grupo escolar, persuadir os demais professores para a efetivação da proposta" (Pertile, 2014, p. 81). Portanto, segundo a autora, esses profissionais recebem uma excessiva responsabilização para a difusão do ideário da educação inclusiva, "sem a consciência do significado que ele carrega e das relações que sustenta".

Nesse sentido, no PNE-Coned afirma-se que para a manutenção de um ensino de qualidade é preciso que "se disponha a investir com seriedade na formação básica e continuada dos profissionais da educação e, de forma mais específica, na formação do magistério para todos os níveis e modalidades educacionais" (Coned, 1997, p. 41). Para isso, apresenta-se como meta habilitar os professores em exercício no prazo máximo de cinco anos. Assim, o documento entende a educação como instrumento de "formação ampla, de luta pelos direitos da cidadania e da emancipação social, preparando as pessoas e a sociedade para a responsabilidade de construir, coletivamente, um projeto de inclusão e de qualidade social para o País" (p. 1), adequado aos interesses da maioria da população.

A concepção de educação presente no plano compreende a escola "como o espaço democrático de elaboração de valores, de tolerância e respeito às diferenças, de produção e disseminação de conhecimento e de convivência humana e social, cultural e política, levando sempre em consideração a realidade das relações sociais e de trabalho" (Coned, 1997, p. 2), opondo-se às concepções que a vinculam à lógica 
globalizante do mercado e que visam formar indivíduos consumidores e competitivos. Contudo, atualmente o foco das políticas educacionais é distribuir educação conforme a necessidade do capital e a capacidade do indivíduo, de forma a não investir mais que o necessário e desde que isso não resulte em conflitos sociais. Assim, tendenciosamente, essas políticas parecem relacionar a educação inclusiva com a inclusão social, indicando que a continuidade das políticas inclusivas é essencial para a expansão do mercado interno (Brasil. MPOG, 2007).

Para sustentar essa concepção, a educação passa a ser tratada como um serviço e a educação especial torna-se expressão e estratégia dessa perspectiva inclusiva orientada pelos pilares da distribuição de renda e ampliação do número de alunos regularmente matriculados no sistema educacional.

Esse contexto, em que se insere o termo "inclusivo" no sistema educacional sob a justificativa de "educação para todos", é marcado por contradições. Conforme Michels e Garcia (2014), o adjetivo "inclusivo" é adicionado como complemento ao "sistema educacional" com um discurso para torná-lo mais democrático, capaz de solucionar problemas sociais como as desigualdades econômicas. A partir da crítica do Banco Mundial ao sistema educacional "tradicional", abrem-se margens à "iniciativa privada" e a "programas não formais" para atuação na oferta da educação das pessoas com deficiência e/ou necessidades educacionais especiais - fato que contribui para uma corrida mercantil em que programas e materiais didáticos são elaborados para serem vendidos ao sistema educacional, coerentes com a lógica privatista da educação.

Essa forma de se referir aos sujeitos público-alvo da educação especial está embasada na ideia de Costas e Tambara (2013), que consideram que nem todas as pessoas com deficiência têm necessidades educacionais especiais e, por outro lado, nem todas as pessoas com necessidades educacionais especiais têm alguma deficiência. Entende-se que a pessoa com necessidades educacionais especiais é aquela que apresenta, de modo permanente ou transitório, algum(a) dificuldade/ transtorno na sua aprendizagem ou, ainda, aquela que, por sua elevada capacidade de aprendizagem, apresenta algum tipo de dificuldade escolar.

Por meio de um discurso que afirma a democratização da educação como um direito subjetivo e constitucional de todos, a educação é oferecida numa lógica de pseudoformação, de uma "educação subalterna" que forma para o trabalho simples. Nessa perspectiva, em que a formação para o trabalho simples está aliada à inserção das pessoas no mercado de trabalho e no sistema econômico, Michels e Garcia (2014, p. 168) afirmam que "sobressai, nesse caso, o esforço do capital para adentrar todos os setores da sociedade, inclusive a educação, buscando transformá-la também em objeto do mercado".

A formação de professores em educação especial, assim como em outras áreas de conhecimento, pode ser entendida pelas políticas atuais como um processo de formação de professores multifuncionais que, centrada em conhecimentos práticos, foi promovida por cursos aligeirados, na modalidade a distância. De acordo 
com Pertile (2014, p. 84), é possível que essa formação seja comprometida, diante do número expressivo e crescente de cursos de especialização a distância, com carga horária mínima de 120 horas, que, em nome da "urgência de formar o profissional para uma tarefa imediata", podem oferecer processos formativos "cuja consistência é questionável". Nesse contexto de ampliação do trabalho do professor de educação especial e de restrição de seu período formativo, a ideia do superprofessor (Evangelista; Triches, 2012) comprometido com esse novo tempo é veiculada pelos slogans educacionais atrelados às políticas públicas, em que se difunde a ideia desse profissional como responsável para dar conta desse universo de exigências que a inclusão escolar passa a exigir.

\section{Considerações finais}

A história da educação brasileira é, em seus diferentes períodos, marcada por avanços e retrocessos, especialmente no campo da educação especial. O PNE-Coned, elaborado democraticamente por diversos setores da sociedade civil, representa os esforços e a preocupação histórica em relação aos rumos do sistema educacional público do Brasil. Um dos pontos destacados no documento que corrobora as mudanças consideradas necessárias na educação é a formação de professores, considerada investimento indispensável a ser realizado. Desse modo, a valorização dos profissionais atuantes na educação básica, em seus processos de formação inicial e continuada, é fundamental para que se supere um tipo de educação aliado aos interesses do capital.

Suspeitamos que as políticas educacionais para a formação de professores vigentes no País podem contribuir para os processos de desintelectualização do professor e da reconversão docente, por fomentarem a formação aligeirada e sem a necessária fundamentação teórica. Esses processos formativos, por serem esvaziados de fundamentos relativos a discussões teórico-políticas, contribuem para a formação de gestores de recursos e técnicas, habilitados a "ensinar tudo a todos". Atribuem-se inúmeras incumbências ao professor de educação especial, que se torna multifuncional e é solicitado a lidar com todas as exigências postas, a partir de uma formação generalista, regulamentada pelas leis.

Entende-se que as políticas atuais para a formação de professores, que atingem também os professores da educação especial, estão voltadas para uma lógica economicista, com processos formativos generalistas diante de um cenário multifacetado para a atuação profissional. A forma como se compreendem os processos formativos dos professores, nas diretrizes atuais, parece estar distanciada do que foi amplamente discutido na elaboração do Plano Nacional de Educação Proposta da Sociedade Brasileira de 1997. Nesse sentido, faz-se necessária a resistência a qualquer modelo de formação de professores que não esteja aliada a projetos educacionais mais democráticos e emancipatórios. 


\section{Referências bibliográficas}

BRASIL. Conselho Nacional de Educação (CNE). Câmara de Educação Básica (CEB). Resolução CNE/CEB no 2, de 11 de setembro de 2001. Institui diretrizes nacionais para a educação especial na educação básica. Brasília, 2001. Disponível em: <http://portal.mec.gov.br/cne/arquivos/pdf/CEB0201.pdf>. Acesso em: abr. 2016.

BRASIL. Conselho Nacional de Educação (CNE). Câmara de Educação Básica (CEB). Resolução $n^{\circ}$ 4, de 2 de outubro de 2009. Institui diretrizes operacionais para o atendimento educacional especializado na educação básica, modalidade educação especial. Brasília, 2009. Disponível em: <http://portal.mec.gov.br/ index.php?option $=$ com_docman\&view $=$ download\&alias $=2135-$ rceb00409resolucao04-cne\&category_slug=dezembro-2009-pdf\&Itemid=30192> Acesso em: abr. 2016.

BRASIL. Conselho Nacional de Educação (CNE). Conselho Pleno (CP). Resolução CNE/CP $n^{\circ}$ 1, de 15 de maio de 2006. Institui as Diretrizes Curriculares Nacionais para o curso de Pedagogia, licenciatura. Brasília, 2006. Disponível em: <http://portal.mec.gov.br/cne/arquivos/pdf/rcp01_06.pdf>. Acesso em: abr. 2016.

BRASIL. Constituição (1988). Constituição da República Federativa do Brasil. Brasília, 1988. Disponível em: < https://www.senado.gov.br/atividade/const/ con1988/CON1988_05.10.1988/CON1988.pdf>.

BRASIL. Lei no 9.394, de 20 de dezembro de 1996. Estabelece as diretrizes e bases da educação nacional. Diário Oficial da União, Brasília, DF, 23 dez. 1996. Seção 1, p. 27833.

BRASIL. Lei no 12.796, de 2 de abril de 2013. Altera a Lei no 9.394 de 20 de dezembro de 1996, que estabelece as diretrizes e bases da educação nacional, para dispor para a formação dos profissionais da educação e dar outras providências. Diário Oficial da União, Brasília, DF, 5 abr. 2013. Seção 1, p. 1.

BRASIL. Ministério da Educação (MEC). Política nacional de educação especial na perspectiva da educação inclusiva. Brasília, 2008. Disponível em:

$<$ http://portal.mec.gov.br/index.php?option =com_ docman\&view $=$ download\&alias $=16690$-politica-nacional-de-educacao-especialna-perspectiva-da-educacao-inclusiva-05122014\&Itemid=30192> . Acesso em: abr. 2016.

BRASIL. Ministério da Educação (MEC). Nota técnica SEESP/GAB/n 9/2010, de 9 de abril de 2010. Orientações para a organização dos centros de atendimento educacional especializado. Brasília: MEC/SEESP, 2010a.

BRASIL. Ministério da Educação (MEC). Nota técnica SEESP/GAB/no 11/2010, de 7 de maio de 2010. Orientações para a institucionalização da oferta do atendimento educacional especializado - AEE - salas de recursos multifuncionais, implantadas nas escolas regulares. Brasília: MEC/ SEESP, 2010b. 
BRASIL. Ministério do Planejamento, Orçamento e Gestão (MPOG). Plano plurianual 2008-2011: projeto de lei. Brasília: MPOG, 2007. Disponível em: $<$ http://www.planejamento.gov.br/secretarias/upload/arquivo/spi-1/ppa1/2008/081015_ppa_2008_mespres.pdf> Acesso em: abr. 2016.

BOLLMANN, M. D. G. N. Revendo o Plano Nacional de Educação: proposta da sociedade brasileira. Educação \& Sociedade, Campinas, v. 31, n. 112, p. 657-676, jul./set. 2010. Disponível em: <http://www.scielo.br/pdf/es/v31n112/02.pdf>.

CELLARD, A. A análise documental. In: POUPART, J. et al. A pesquisa qualitativa: enfoques epistemológicos e metodológicos. Petrópolis: Vozes, 2008. p. 295-316.

CONGRESSO NACIONAL DE EDUCAÇÃO (Coned). Plano Nacional de Educação Proposta da Sociedade Brasileira. Belo Horizonte: [s.n.], 1997. Disponível em: <http://www.adusp.org.br/files/PNE/pnebra.pdf> [sem paginação].

COSTAS, F. A. T.; TAMBARA, K. G. A nova Política Nacional de Educação Especial no Brasil e suas decorrências para o atendimento de alunos com transtornos de aprendizagem. In: CONGRESSO INTERNACIONAL GALEGO-PORTUGUÊS DE PSICOPEDAGOGIA, 12., 2013, Braga, Portugal. Atas... Braga: Centro de Investigação em Educação; Instituto de Educação, Universidade do Minho, 2013. p. 423-438.

EVANGELISTA, O.; TRICHES, J. Curso de pedagogia, organizações multilaterais e o superprofessor. Educar em Revista, Curitiba, n. 45, p. 185-198, jul./set. 2012.

GARCIA, R. M. C. Política de educação especial na perspectiva inclusiva e a formação docente no Brasil. Revista Brasileira de Educação, Rio de Janeiro, v. 18, n. 52, p. 101-119, jan./mar. 2013.

GARCIA, R. M. C. Para além da "inclusão": crítica às políticas educacionais contemporâneas. In: EVANGELISTA, O. (Org.). O que revelam os slogans na política educacional. Araraquara: Junqueira \& Marin, 2014. p. 101-140.

MICHELS, M. H. O instrumental, o gerencial e a formação a distância: estratégias para a reconversão docente na perspectiva da educação inclusiva. In: CAIADO, K. R. M.; JESUS, D. M.; BAPTISTA, C. R. (Org.). Professores e educação especial: formação em foco. Porto Alegre: Mediação, 2011. p. 79-90.

MICHELS, M. H.; GARCIA, R. M. C. Sistema educacional inclusivo: conceito e implicações na política educacional brasileira. Cadernos CEDES, Campinas, v. 34, n. 93, p. 157-173, 2014.

PERTILE, E. B. Sala de recursos multifuncional: a proposta oficial para o trabalho docente frente às necessidades educacionais dos alunos com deficiência intelectual. 2014. 165 f. Dissertação (Mestrado em Educação) - Centro de Educação, Comunicação e Artes, Universidade Estadual do Oeste do Paraná, Cascavel, 2014. Disponível em < http://tede.unioeste.br/tede//tde_busca/arquivo. php?codArquivo=1446>. Acesso em: 8 jan. 2016 . 
SHIROMA, E.; SANTOS, F. A. Slogans para a construção do consentimento ativo. In: EVANGELISTA, O. (Org.). O que revelam os slogans na política educacional. Araraquara: Junqueira \& Marin, 2014. p. 21-46.

Mariana Luzia Corrêa Thesing é mestra em Educação pela Pontifícia Universidade Católica do Rio Grande do Sul (PUC-RS) e doutoranda em Educação pelo Programa de Pós-Graduação em Educação da Universidade Federal de Santa Maria (PPGE/UFSM).

marluzcor@gmail.com

Ana Paula dos Santos Ferraz é pós-graduada lato sensu em Gestão Educacional e mestranda em Educação na Universidade Federal de Santa Maria (UFSM).

anapaulaferrazeducadora@hotmail.com

Bruna de Assunção Medeiros, pós-graduada lato sensu em Atendimento Educacional Especializado pela Universidade Federal do Ceará (UFC) e mestranda em Educação na Universidade Federal de Santa Maria (UFSM), é revisora de texto braille no Instituto Federal Farroupilha.

bruna.medeiros@iffarroupilha.edu.br

Fabiane Adela Tonetto Costas, doutora em Educação pela Universidade Federal do Rio Grande do Sul (UFRGS), é professora associada II do Departamento de Fundamentos da Educação e do Programa de Pós-Graduação em Educação da Universidade Federal de Santa Maria (CE/PPGE/UFSM).

fabicostas@gmail.com 